\title{
Respostas fisiológicas de folhas de couve minimamente processadas
}

Marcelo Augusto G. Carnelossi'; ${ }^{1}$ Ebenézer de O. Silva² ${ }^{2}$ Rodrigo da S. Campos ${ }^{3}$; Rolf Puschmann ${ }^{3}$

${ }^{1}$ UFS, Depto. Eng. Química, 49100-000 São Cristóvão-SE; E-mail: carnelossi@ ufs.br; 2Embrapa Agroindústria Tropical, 60511-110 Fortaleza-CE; ${ }^{3}$ UFV, Depto. Biol. Vegetal, 36571-000 Viçosa-MG

\section{RESUMO}

Verificou-se a taxa respiratória, a produção de etileno de folhas de couve intactas e minimamente processadas, e a influência do horário de colheita, do resfriamento rápido e da temperatura de sanitização sobre a conservação do produto minimamente processado. Folhas de couve totalmente desenvolvidas foram colhidas às sete e às 14 horas, na horta da UFV, entre 1996 e 2000 . O processamento foi realizado logo após a colheita e após a refrigeração $\left(6 \pm 1^{\circ} \mathrm{C}\right.$ por 8 h). Amostras (200 g) foram acondicionadas em embalagens de poliolefina multicamada, armazenadas a $5 \pm 2^{\circ} \mathrm{C}$ por 15 dias e foram avaliadas quanto aos teores de vitamina $\mathrm{C}$ e atividade de polifenoloxidase (PPO). A taxa respiratória e produção de etileno foram determinadas em folhas intactas e minimamente processadas colocadas em bandejas plásticas e frascos de vidros hermeticamente fechados, e armazenadas durante 24 horas a $1 ; 5 ; 10$ e $25^{\circ} \mathrm{C}$. A taxa respiratória e a evolução de etileno das folhas de couve inteira aumentaram imediatamente após destacamento da planta mãe. $O$ fatiamento aumentou a taxa respiratória da folha em aproximadamente duas vezes. $\mathrm{O}$ aumento da temperatura influenciou significativamente $(\mathrm{P}<0,05 \%)$ a taxa respiratória e a produção de etileno. $\mathrm{O}$ resfriamento rápido reduziu o metabolismo, mas não aumentou o tempo de armazenamento. A baixa temperatura de sanitização é importante para a conservação da couve minimamente processada. $\mathrm{O}$ horário de colheita influenciou significativamente $(\mathrm{P}<0,05 \%)$ a taxa respiratória e a atividade de $\mathrm{PPO}$ da couve minimamente processada, mas não influenciou o tempo de armazenamento.

Palavras-chave: Brassica oleracea cv.acephala, taxa respiratória, etileno, polifenol oxidase, vitamina $\mathrm{C}$, conservação.

\begin{abstract}
Physiological response of kale leaves minimally processed

The respiratory rate and ethylene production were evaluated in whole and minimally processed kale leaves and, the influence of harvest time, of fast cooling and sanitization temperature on the conservation of the minimally processed product. Totally developed kale leaves were harvested at 7 and 14 o'clock in the field, during the years 1996 and 2000. Processing was carried out soon after harvest and subsequent refrigeration $\left(6 \pm 1^{\circ} \mathrm{C}\right.$ for $\left.8 \mathrm{~h}\right)$. Samples $(200 \mathrm{~g})$ were conditioned in multilayer poliolefina packing, stored at $5 \pm 2^{\circ} \mathrm{C}$ for 15 days and evaluate for vitamin $\mathrm{C}$ and polifenoloxidase (PPO) activity. The respiratory rate and production of ethylene were determined in whole leaves as well as in minimally processed ones, packed in plastic trays and glass jars hermetically closed. The packs were stored during 24 hours under temperatures of $1 ; 5 ; 10$ and $25^{\circ} \mathrm{C}$. The respiratory rate and the ethylene production increased immediately after the detachment of the leaves from the mother plant. Cutting increased the respiratory rate in approximately two-folds. Increasing of the temperature affected significantly $(\mathrm{P}<0,05 \%)$ the respiratory rate and the production of ethylene. Fast cooling reduced the metabolism, but did not result in greater storage time. The low temperature during sanitization is important for the conservation of the minimally processed kale. The harvest time influenced significantly $(\mathrm{P}<0,05 \%)$ the respiratory rate and PPO activity of the minimally processed kale, but did not influence the storage time.
\end{abstract}

Keywords: Brassica oleracea L. var. acephala, respiratory rate, ethylene, poliphenol oxidase, ascorbic acid, storage.

(Recebido para publicação em 8 de janeiro de 2004 e aceito em 8 de fevereiro de 2005)

$\mathrm{N}$ os últimos anos, tem-se verificado grande interesse na produção de frutos e hortaliças minimamente processados, tanto ao nível familiar, como nos restaurantes e hotéis. O processamento mínimo de hortaliças inclui operações de seleção, lavagem, classificação, fatiamento, sanitização, centrifugação, embalagem e refrigeração, realizadas de modo a obter-se um produto comestível fresco e que não necessite de preparo subseqüente. No entanto, essas operações causam injúrias ou ferimentos que diminuem a qualidade e o tempo de vida do produto (WILEY, 1994; MORETTI, 2002).

Dentre os efeitos fisiológicos estimulados pelo processamento mínimo, o aumento da taxa respiratória e a síntese de etileno são os que mais influenciam a estabilidade do produto (ABELES et al., 1992; BRECHT, 1995). A taxa respiratória de algumas hortaliças utilizadas em saladas, como alface, cenoura, cebola, rabanete, aipo e chicória, quando cortadas, embaladas e armazenadas, aumenta em relação àquela dos produtos intactos e armazenados a $4,4^{\circ} \mathrm{C}$ (PRIEPKE et al., 1976). Em tomate, o corte em pequenos discos causou aumento na produção de etileno, em torno de 20 vezes, em comparação com a evolução de etileno em frutos intactos, sendo esse aumento notado 15 a 20 minutos após o corte (LEE et al., 1970). Cantwell (1992) verificou em repolho aumento de duas a cinco vezes da taxa respiratória em relação ao produto intacto dependendo da temperatura de armazenamento. Em batata-doce o processamento mínimo causou aumento pronunciado na taxa respiratória logo após o processamento. (MORETTI et al., 2002). Resultados semelhantes também foram verificados por Vitti et al. (2003) em beterrabas minimamente processadas.

$\mathrm{O}$ aumento da taxa respiratória e da produção de etileno em produtos minimamente processados pode ser reduzido de diversas formas; dentre elas o armazenamento em baixa temperatura, associado com atmosfera modificada por embalagens apropriadas, como ocorre com alface fatiada (SINGH et al., 1972), com couve-brócolos (BARTH et al., 1993), couve (SARANTOPOULOS et al., 2002), batata-doce (MORETTI et al., 2002) e beterraba (VITTI et al.,2003). 

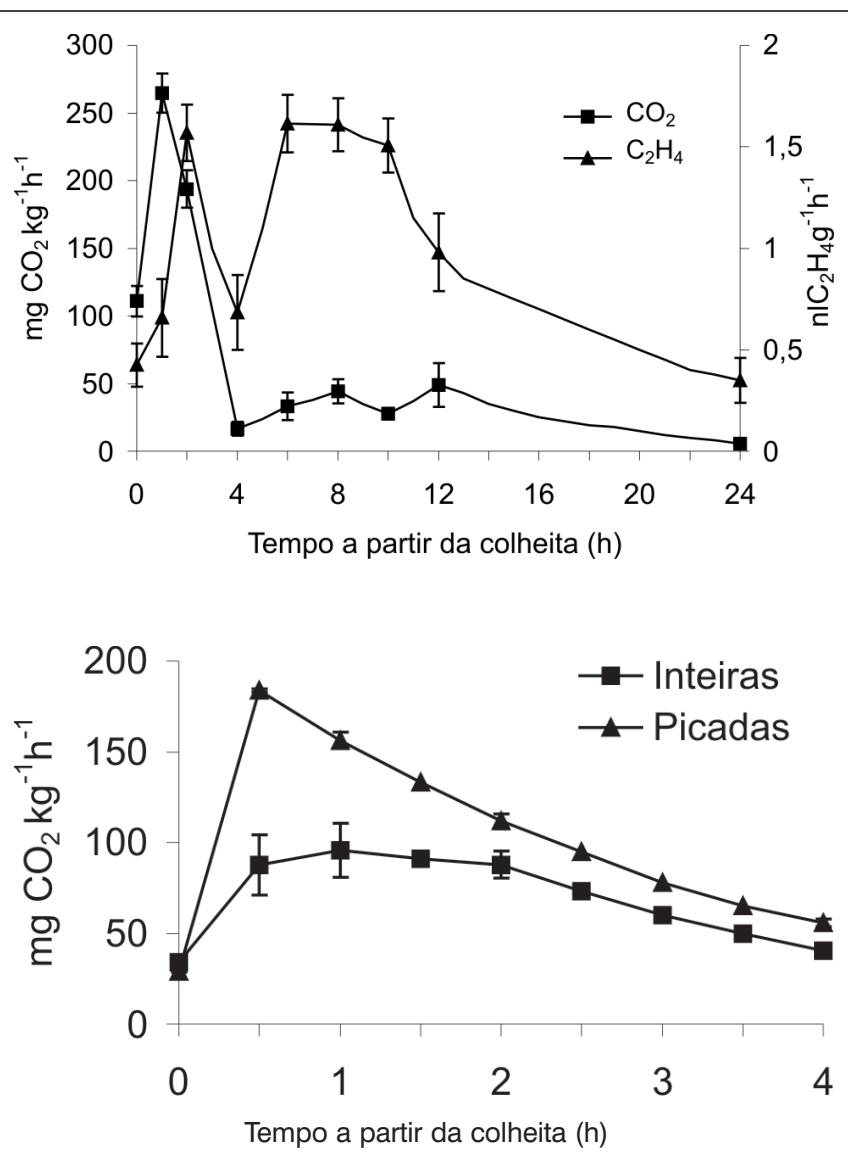

Figura 1. Taxa respiratória e produção de etileno de folhas de couve inteiras (A); taxa respiratória de folhas inteiras e minimamente processadas (B), mantidas a $25^{\circ} \mathrm{C}$. As barras representam o erro padrão da média. Viçosa, UFV, 2000.

As mudanças na taxa respiratória e produção de etileno dificultam o trabalho com produtos minimamente processados. Assim, o controle da temperatura passa a ser a técnica mais eficiente e importante disponível para minimizar os efeitos do processamento mínimo em tecidos vegetais, uma vez que reações metabólicas são reduzidas de duas a três vezes a cada redução de $10^{\circ} \mathrm{C}$ na temperatura (BRECHT, 1995). Cantwell (1992) afirma que o controle da temperatura após o processamento é crítico para diminuir a atividade metabólica induzida pelo processamento. Assim, o resfriamento rápido ou o uso de baixas temperaturas durante a sanitização podem ser eficientes na manutenção da qualidade da couve minimamente processada.

O processamento mínimo resulta em aumento da atividade de algumas enzimas do metabolismo vegetal, tais como catalase, peroxidase, polifenol oxidase, e fenilalanina amônia-liase (BOLIN; HUXSOLL, 1991). Essas enzimas causam o aparecimento de odores ("off flavors"), escurecimento do vegetal e lignificação da parede celular, diminuindo a qualidade do produto (BRECHT, 1995). Vários métodos têm sido propostos para a diminuição da atividade enzimática e a prevenção do escurecimento enzimático de produtos minimamente processados. Os mais utilizados são o armazenamento a baixas temperaturas, utilização de atmosfera modificada e inibidores (NICOLI et al., 1994).

O estado hídrico das folhas varia, durante o dia, de acordo com as condições edafo-climáticas e pode influenciar a senescência e a longevidade pós-colheita (THOMAS; STODDART, 1980). O efeito do horário de colheita das folhas de couve sobre a longevidade do produto minimamente processado é desconhecido. Entretanto, tais informações são de grande utilidade para a indústria de processamento mínimo, pois poderiam viabilizar a colheita e o processamento de couve em diferentes horários, bem como a obtenção de produtos com alta qualidade e maior vida de prateleira.

O presente trabalho teve por finalidade investigar os efeitos do processamento mínimo de folhas de couve sobre a taxa respiratória, a produção de etileno, bem como verificar a influência do horário de colheita, do resfriamento rápido e da temperatura de sanitização sobre a conservação do produto.

\section{MATERIAL E MÉTODOS}

Folhas de couve (Brassica oleracea L. var. acephala) foram colhidas às sete e às 14 horas, com aproximadamente 35 a $40 \mathrm{~cm}$ de comprimento, na horta da Universidade Federal de Viçosa, entre 1996 e 2000. Após a colheita, as folhas foram imediatamente levadas ao laboratório e colocadas em bandejas com o pecíolo imerso em água comum e mantidas à temperatura de $22 \pm 2^{\circ} \mathrm{C}$. Parte das folhas colhidas foi refrigerada por 4 a 8 horas, em câmara fria, a $6 \pm 1{ }^{\circ} \mathrm{C}$, até o seu processamento. Outra parte das folhas foi minimamente processada logo após a colheita.

Para determinação da taxa respiratória e evolução de etileno foram compostos 18 tratamentos, arranjados em esquema fatorial 2 (inteiro e fatiado) $\mathrm{x}$ 9 (tempos de amostragem), no delineamento experimental inteiramente casualizado, com quatro repetições. Cada unidade experimental foi constituída de uma bandeja 6,0 L e frascos de 1,5 L. Para os experimentos com horário de colheita, resfriamento rápido e temperatura de sanitização e conservação, foram compostos 32 tratamentos, arranjados em esquema fatorial 2 (horários de colheita) x 2 (tratamentos de resfriamento) x 2 (temperaturas de sanitização) x 4 (tempos de amostragem), no delineamento experimental inteiramente casualizado, com quatro repetições.

O processamento mínimo constituiu-se das etapas de seleção, padronização, lavagem com água, fatiamento (espessuras de 1-3 mm), sanitização 10 minutos (150 $\mathrm{mg} \mathrm{L}^{-1}$ de cloro ativo, a 
$22 \pm 2^{\circ} \mathrm{C}$ e $\left.5 \pm 1^{\circ} \mathrm{C}\right)$, enxágüe $\left(3 \mathrm{mg} \mathrm{L}{ }^{-1}\right.$ de cloro ativo), centrifugação por $10 \mathrm{mi}-$ nutos $(800 \mathrm{x} g$ ) e embalagem.

Amostras contendo $200 \mathrm{~g}$ de couve minimamente processada foram acondicionadas em embalagens de poliolefina multicamada (Cryovac, PD 941), com permeabilidades, nas condições normais de temperatura e pressão (CNTP), de 16500 e $32000 \mathrm{~cm}^{3} \mathrm{~m}^{-2} \mathrm{dia}^{-1}$ para $\mathrm{O}_{2}$ e $\mathrm{CO}_{2}$, respectivamente, e de 5 $\mathrm{g} \mathrm{m}^{-2}$ dia $^{-1}$ para $\mathrm{H}_{2} \mathrm{O}$. As embalagens (18 $\mathrm{cm}$ de largura e $22 \mathrm{~cm}$ de comprimento) foram armazenadas em expositores verticais a $5^{\circ} \mathrm{C}$, por 15 dias. Durante o armazenamento, foram retiradas amostras para determinação do teor de vitamina $\mathrm{C}$ e da atividade enzimática da polifenol oxidase (PPO).

Para a determinação da taxa respiratória e da produção de etileno, folhas intactas $(300 \mathrm{~g})$ e folhas minimamente processadas foram colocadas em bandejas plásticas de 6,0 L e frascos de 1,7 $\mathrm{L}$, respectivamente. Foram mantidos hermeticamente fechados à temperatura ambiente $\left(25 \pm 2^{\circ} \mathrm{C}\right)$ e temperaturas de $1 ; 5 ; 10$ e $25^{\circ} \mathrm{C}$. Amostras de gase da atmosfera interna dos frascos foram retiradas para análises cromatográficas a cada 15 minutos, durante duas horas, até completar 12 horas.

Os teores de vitamina $\mathrm{C}$ foram determinados de acordo com a metodologia proposta pela American Official Analysis of Chemistry, com algumas adaptações. Amostras de $10 \mathrm{~g}$ de material fresco foram maceradas em almofariz, contendo nitrogênio líquido, suspensa com solução de extração (ácido metafosfórico $\left(\mathrm{HPO}_{3}\right)_{\mathrm{n}}$ em ácido acético glacial), filtrada em gaze e o volume completado para $50 \mathrm{ml}$ em balão volumétrico. A titulação foi realizada utilizando 2,6diclorofenolindofenol contendo $42 \mathrm{mg}$ de $\mathrm{NaHCO}_{3}$. A vitamina $\mathrm{C}$ foi expressa em mg $100 \mathrm{~g}^{-1}$ massa fresca.

A atividade da polifenol oxidase (PPO) foi determinada de acordo com método descrito por Almeida e Nogueira (1995), com adaptações. O extrato enzimático de couve foi obtido homogeneizando-se $5 \mathrm{~g}$ de folhas em 50 $\mathrm{ml}$ de solução tampão fosfato $0,1 \mathrm{M}, \mathrm{pH}$ 6,0 , a $4^{\circ} \mathrm{C}$. O homogenato foi centrifugado a $25.000 \mathrm{x} \mathrm{g}$, por $20 \mathrm{~min}$ a $4^{\circ} \mathrm{C}$ e o sobrenadante obtido foi utiliza-

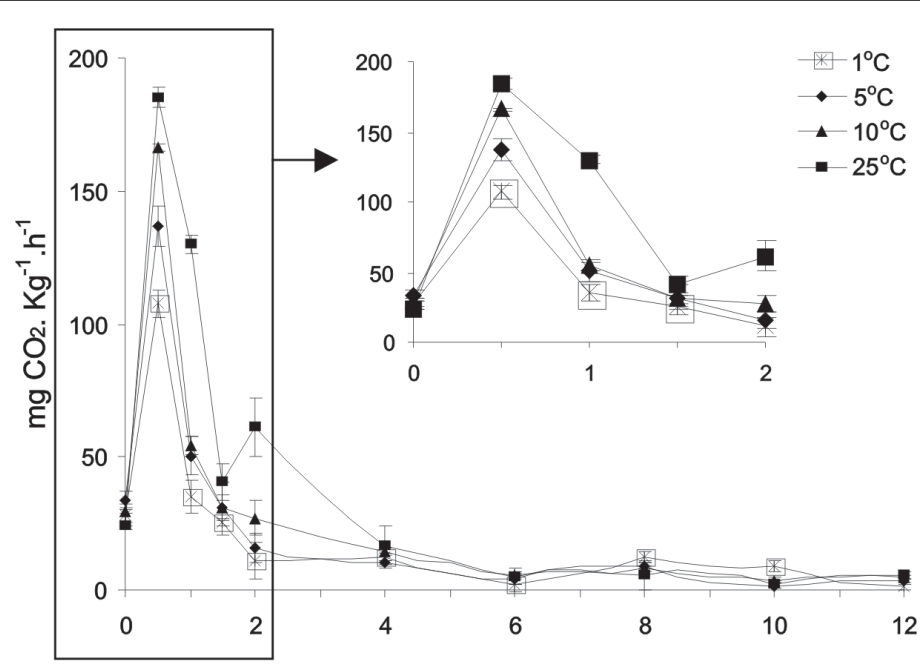

Tempo a partir da colheita (h)

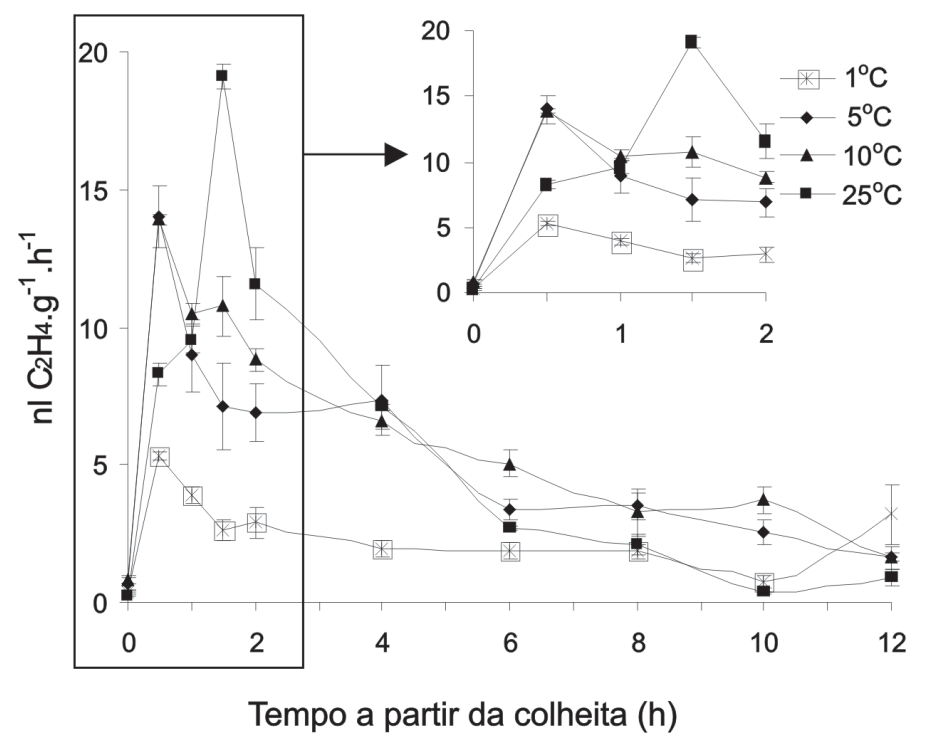

Figura 2. Taxa respiratória e evolução de etileno de folhas de couve minimamente processadas mantidas a $1,5,10$ e $25^{\circ} \mathrm{C}$. As barras representam o erro padrão da média. Viçosa, UFV, 2000.

do como extrato enzimático. $\mathrm{O}$ meio de reação foi composto de $1,3 \mathrm{ml}$ de tampão fosfato $0,1 \mathrm{M}, \mathrm{pH}$ 6,0 e 1,0 ml de catecol 0,1 M, colocados em cubeta de $3 \mathrm{~cm}^{3}$, na qual foram adicionados 0,2 $\mathrm{ml}$ de extrato enzimático para dar início à reação que foi realizada a $30^{\circ} \mathrm{C}$. Imediatamente após a mistura, foi lida a absorvância a $425 \mathrm{~nm}$, por $3 \mathrm{~min}$ em um espectrofotômetro de feixe duplo (Mod. U-2000, Hitachi), previamente calibrado com a solução tampão fosfato $0,1 \mathrm{M}$. Um controle contendo somente solução tampão e catecol foi utilizado para detectar eventual contribuição de reações não enzimáticas. Uma unidade de polifenol oxidase foi definida como a quantidade de enzima no extrato capaz de aumentar a absorvância em 0,001 unidade por minuto. A atividade foi expressa em unidades de PPO $\mathrm{min}^{-1} \mathrm{~mL}^{-1}$ $\mathrm{g}^{-1}$ massa fresca.

Os dados foram submetidos à análise de variância e desvio padrão, sendo que diferenças entre dois tratamentos maiores que a soma de dois desvios padrões foram consideradas significativas $(\mathrm{P}<0,05 \%)$.

\section{RESULTADOS E DISCUSSÃO}

A taxa respiratória das folhas de couve inteiras aumentou logo após o desta- 

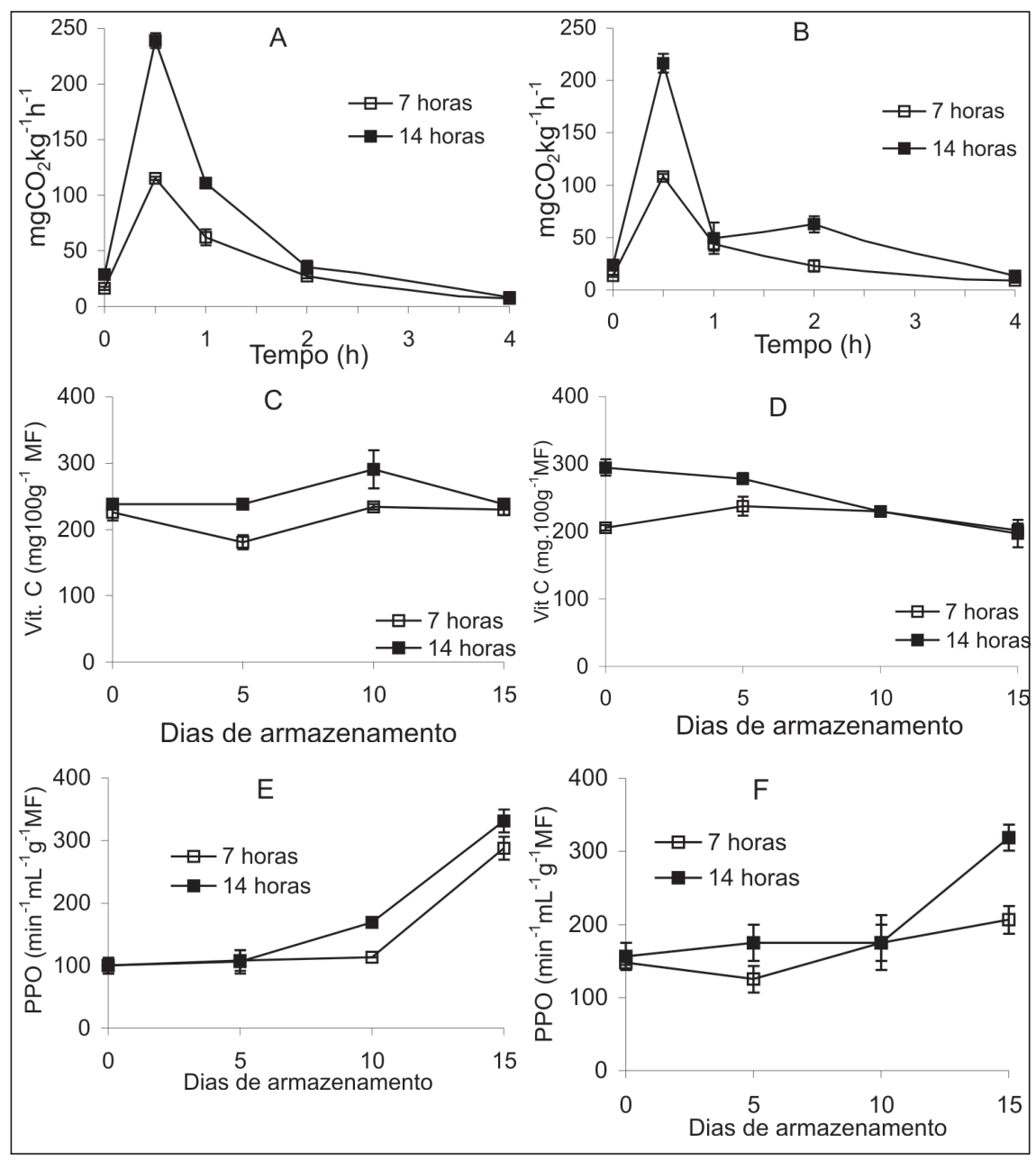

Figura 3. Taxa respiratória, teores de vitamina $\mathrm{C}$ e atividade de polifenoloxidase (PPO) de folhas de couve colhidas às $7 \mathrm{e}$ às 14 horas, minimamente processadas recém-colhidas $(\mathrm{A}, \mathrm{C}$ e E) ou pré-resfriadas (B, D e F). As barras representam o erro padrão da média. Viçosa, UFV, 2000.

camento da planta mãe, caindo consideravelmente após uma hora (Figura 1A). A produção de etileno apresentou perfil semelhante, com acentuada elevação com a colheita das folhas, tendo chegado à máxima produção após duas horas e estabilizando-se entre seis e dez horas (Figura 1A). Esse aumento na taxa respiratória e na produção de etileno, logo após a colheita, de acordo com Watada et al. (1990), está relacionado às reações bioquímicas e fisiológicas que se tornam mais ativas, em resposta ao estresse da colheita, de forma a restabelecer o estado de equilíbrio energético que a folha possuía anteriormente, quando estava ligada à planta mãe.

A maior taxa respiratória das folhas de couve minimamente processadas (Figura 1B) provem do estresse provoca- do pelo fatiamento delas. De acordo com Sakr et al. (1997), o aumento da taxa respiratória e da produção de etileno pode ser uma resposta hormonal e bioquímica devido ao estresse causado pelo corte. Isso ocorre pois o primeiro alvo desse estresse é a membrana plasmática, que responde com mudanças em suas características físicas, de forma a contornar tais perturbações e tentar reparar os danos causados durante o processamento (WATADA et al., 1990, SAKR et al., 1997). Aumentos da taxa respiratória do produto cortado em relação ao intacto também foram observados por Priepke et al. (1976) e Moretti et al. (2002), em batata-doce; Vitti et al. (2003), em beterraba, Cantwell (1992), em repolho e Artés et al. (1999), em tomates minimamente processados. Watada et al. (1996) observaram que em alface, a $5^{\circ} \mathrm{C}$, a taxa respiratória do produto minimamente processado aumentou em média $193,1 \%$, em relação ao produto inteiro.

O armazenamento refrigerado influenciou significativamente a taxa respiratória (Figura 2A) e a evolução de etileno (Figura 2B) do produto minimamente processado. Esses resultados são semelhante àqueles observados por Cantwell (1992), Brecht (1995), Watada et al. (1996) e Artés et al. (1999) em produtos minimamente processados, quando houve aumento da taxa respiratória com a temperatura.

A taxa respiratória das folhas colhidas às 14 horas e minimamente processadas logo após a colheita foi cerca de duas vezes maior do que daquelas colhidas às sete horas (Figura 3A). Essa diferença foi mantida mesmo quando a couve foi resfriada antes de seu processamento (Figura 3B). A temperatura ambiente, durante a colheita às sete horas, estava em torno de $13^{\circ} \mathrm{C}$, enquanto que às 14 horas, estava em torno de $28^{\circ} \mathrm{C}$. Esta alta temperatura poderia explicar, pelo menos em parte, a alta taxa respiratória do produto uma vez que ambos foram minimamente processados uma hora após a colheita. Por esse resultado conclui-se ser importante observar o horário de colheita.

Após o resfriamento rápido e sanitização a $22 \pm 2^{\circ} \mathrm{C}$, as folhas de couve apresentaram taxas respiratórias $50 \%$ menores do que aquelas processadas logo após a colheita e sanitizadas a $22 \pm 2{ }^{\circ} \mathrm{C}$ (Figura 4A). Por outro lado, a sanitização a $5^{\circ} \mathrm{C}$ causou redução de aproximadamente $25 \%$ na taxa respiratória do produto resfriado (Figura 4B). No entanto, os produtos processados após resfriamento apresentaram o mesmo padrão respiratório, quando sanitizados tanto a $22 \pm 2^{\circ} \mathrm{C}$ como a $5^{\circ} \mathrm{C}$ (Figura $4 \mathrm{~A} \mathrm{e}$ $4 \mathrm{~B})$. Isso mostra que o resfriamento rápido, a $6 \pm 1^{\circ} \mathrm{C}$, por aproximadamente seis horas, foi suficiente para diminuir o metabolismo da folha inteira.

$\mathrm{O}$ teor de vitamina $\mathrm{C}$ do produto processado logo após a colheita às 14 horas e armazenado, manteve-se mais elevado, até 10 dias (Figura 3C). Nos produtos processados, após resfriamento rápido (Figura 3D), o teor de vitamina $\mathrm{C}$ manteve-se maior naqueles colhidos às 14 horas, com até cinco dias de 
armazenamento. Ao final dos 15 dias de armazenamento, os teores de vitamina $\mathrm{C}$, dos produtos colhidos em diferentes horários foram os mesmos em todas as amostras (Figura 3C e 3D), sugerindo, assim, um mesmo tempo de vida de prateleira para todos os tratamentos.

Amarante e Puschmann (1993) observaram, em folhas de couve inteiras colhidas às 13 horas e mantidas no escuro, menores perdas pós-colheita de qualidade nutricional, em função do teor de vitamina $\mathrm{C}$, e atraso na senescência em dois dias, em relação àquelas colhidas às seis horas, mantidas nas mesmas condições. No presente trabalho, observou-se para folhas minimamente processadas pequeno aumento nos teores de vitamina $\mathrm{C}$ nos produtos colhidos às 14 horas, em relação àquelas colhidas às sete horas. Essa diferença, no entanto, não resultou em maior tempo de vida de prateleira da couve minimamente processada. Dessa forma, para o processamento, a colheita das folhas de couve pode ser realizada em qualquer horário do dia.

Verificou-se também em todos os tratamentos, redução nos teores de vitamina $\mathrm{C}$, ao longo do tempo de armazenamento (Figura 4C e 4D). No entanto, para couve sanitizada a $22 \pm 2^{\circ} \mathrm{C}$, após resfriamento rápido, os teores de vitamina $\mathrm{C}$, após 15 dias de armazenamento, foram $25 \%$ menores do que naquelas sanitizadas a $22 \pm 2^{\circ} \mathrm{C}$, recém-colhidas (Figura 4C). O processamento imediatamente após a colheita resultou em aproximadamente $50 \%$ de redução do teor de vitamina $\mathrm{C}$ após 10 dias de armazenamento a $5^{\circ} \mathrm{C}$ (Figura 4C e 4D).

A atividade da polifenol oxidase das folhas de couve minimamente processadas em função do tempo de armazenamento foi influenciada pelo horário de colheita (Figura 3E e 3F). Verificou-se, após 10 dias de armazenamento do material colhido às sete horas e processado logo após a colheita (Figura 3E), atividade de PPO significativamente menor do que naquelas que foram colhidas durante a tarde (Figura 3E). Quando o produto foi rapidamente resfriado, antes do processamento, a atividade de PPO na couve armazenado foi constante até o $10^{\circ}$ dia de armazenamento, tanto naque-
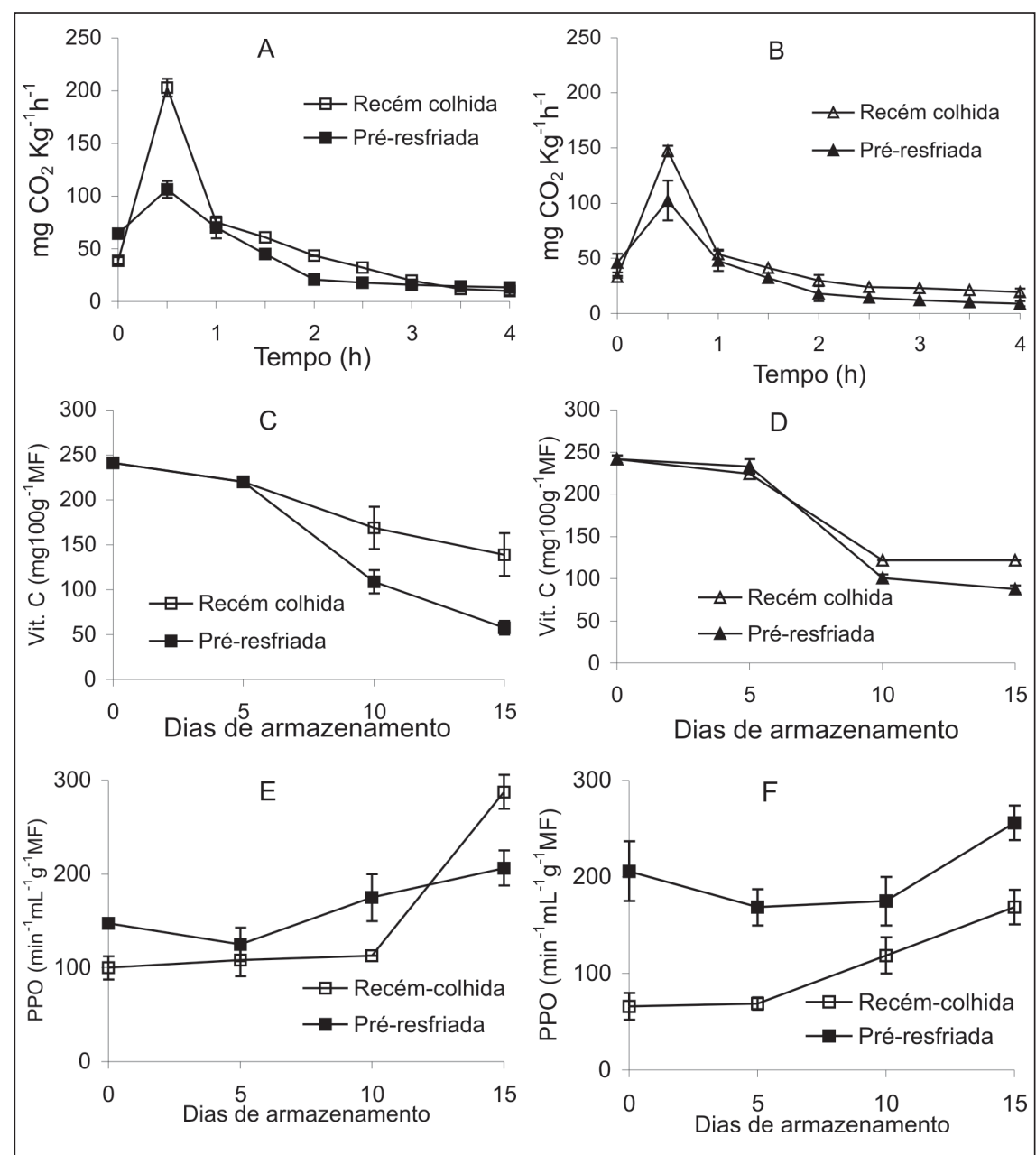

Figura 4. Taxa respiratória, teores de vitamina $\mathrm{C}$ e atividade de polifenol oxidase (PPO) de folhas de couve minimamente processadas recém-colhidas ou pré-resfriadas e sanitizadas a $22 \pm 2^{\circ} \mathrm{C}\left(\mathrm{A}, \mathrm{C}\right.$ e E) e a $5^{\circ} \mathrm{C}\left(\mathrm{B}, \mathrm{D}\right.$ e F), armazenadas em embalagens PD941 a $5^{\circ} \mathrm{C}$. As barras representam o erro padrão da média. Viçosa, UFV, 2000.

les provenientes da colheita às sete horas, como às 14 horas (Figura 3F). Após 10 dias de armazenamento, os produtos colhidos às 14 horas apresentaram maior atividade de PPO (Figura 3F). Esses resultados estão relacionados com o maior metabolismo do produto no período da tarde, devido à alta temperatura. Com o metabolismo mais acentuado, ocorre aumento nos conteúdos de fenóis e de PPO, os quais irão causar escurecimento no produto minimamente processado, aparecimento de cheiro desagradável, diminuindo, assim, a qualidade do produto (BOLIN; HUXSOLL, 1991; BRECHT, 1995).

A atividade de PPO de folhas de couve minimamente processadas foi, em geral, maior naqueles rapidamente resfriadas até 10 dias (Figura 4E) em relação àqueles processados logo após a colheita, independente da temperatura de sanitização. Em todos os tratamentos, observou-se aumento na atividade da PPO, em função do tempo de armazenamento, e esse aumento foi relativamente maior nos produtos processados quando recém-colhidos (Figura 4E e 4F). Produtos recém-colhidos, processados e sanitizados a $5^{\circ} \mathrm{C}$, apresentaram atividade de PPO menor do que aqueles sanitizados a $22 \pm 2^{\circ} \mathrm{C}$ (Figura $4 \mathrm{~F}$ ). Esse comportamento deve-se à baixa atividade enzimática do produto naquela temperatura.

A enzima PPO está relacionada ao escurecimento do tecido (WHITAKER; LEE, 1995) e sua maior atividade com o tempo de armazenamento, tanto nos produtos recém-colhidos quanto naqueles rapidamente resfriados, ocorre em conseqüência do processo de senescência. Esse aumento pode estar 
relacionado com a produção de etileno, que é acentuada durante a senescência (BOLIN; HUXSOLL, 1991).

Os resultados indicaram que a utilização de baixa temperatura $\left(5^{\circ} \mathrm{C}\right) \mathrm{du}$ rante a sanitização é importante para a redução da taxa respiratória do produto minimamente processado, como preconizado por Watada et al. (1996). O resfriamento rápido da couve intacta parece não ter aumentado o tempo de vida de prateleira da couve minimamente processada, uma vez que os teores de vitamina $C$ não diferiram com o tempo de armazenamento, tanto para os produtos recém-colhidos como para aqueles rapidamente resfriados. Com base nas diferenças verificadas nos teores de vitamina $\mathrm{C}$ e atividade de PPO, a conservação da couve minimamente processada e sanitizada a $5^{\circ} \mathrm{C}$ foi maior do que naquela sanitizada a $22 \pm 2^{\circ} \mathrm{C}$.

De modo geral, o resfriamento rápido das folhas de couve, antes do processamento, apenas reduz seu metabolismo, mas não aumenta o tempo de armazenamento. No entanto, a temperatura de sanitização é um fator importante para a conservação da couve minimamente processada, contribuindo para obtenção de um produto de boa qualidade. Por outro lado, o horário de colheita das folhas de couve não influenciou o tempo de armazenamento do produto minimamente processado. Assim, as agroindústrias de processamento mínimo, poderiam processar a couve continuamente, desde que sob baixas temperaturas. Dessa maneira podese obter um produto com alta qualidade $\mathrm{e}$ maior vida de prateleira.

\section{AGRADECIMENTOS}

À CAPES, pela concessão da bolsa de doutorado, ao PRODETAB e FAPEMIG pelo apoio financeiro.

\section{LITERATURA CITADA}

ABELES, F.B.; MORGAN, P.W.; SALTVEIT JUNIOR.; M.E. Ethylene in plant biology. California: Academic Press, 1992. 414 p.

ALMEIDA, M.E.M.; NOGUEIRA, J.N. The control of polyphenol oxidase activity in fruits and vegetables. A study of the iterations between the chemical compounds used and heat treatment. Plant Foods Human Nutrition, v.47, p.245-256, 1995.

AMARANTE, C.V.T.; PUSCHMANN, R. Relação entre horário de colheita e senescência em folhas de couve. Revista Brasileira Fisiologia Vegetal, v.5, n.1, p.25-29, 1993.

ARTÉS, F; CONESA, M.A.; HERNÁNDEZ, S.; GIL, M.I. Keeping quality of fresh-cut tomato. Postharvest Biology Technology, v.17, p.153-162, 1999.

BARTH, M.M.; KERBEK, E.L.; PERRY, A.K.; SCHMIDT, S.J. Modified atmosphere packaging affects ascorbic acid, enzyme activity and market quality of broccoli. Journal of Food Science, v.58, n.1, p.140-143, 1993.

BOLIN, H.R.; HUXSOLL, C.C. Control of minimally processed carrot (Daucus carota) surface discoloration caused by abrasion peeling. Journal Food Science, v.56, n.2, p.416-418, 1991. BRECHT, J.K., Physiology of lightly processed fruits and vegetables. HortScience, v.30, n.1, p.1822, 1995.

CANTWELL, M. Postharvest handling systems: minimally processed fruits and vegetables. In: KADER, A.A. (Ed.). Phostharvest technology of horticultural crops. 2.ed. Daves: Univ. California, Division of horticulture and natural resources, 1992. p.277-281.

LEE, T.H.; McGLASSON, W.B.; EDWARDS, R.A. Physiology of disks of irradiated tomato fruit. I. Influence of cutting and infiltration on respiration, ethylene production and ripening. Radiation Botany, v.10, p.521, 1970.
MORETTI, C.L.; MAROUELLI, W.A.; SILVA, W.L.C. Respiratory activity and browning of minimally processed sweet potatoes. Horticultura Brasileira, Brasília, v.20, p.497-500, 2002

NICOLI, M.C.; ANESE, M.; SEVERINI, C. Combined effects in preventing enzymatic browning reactions in minimally processed fruit. Journal Food Quality, v.17, p.221-229, 1994.

PRIEPKE, P.E.; WEI, L.S.; NELSON, A.I. Refrigerated storage of prepackaged salad vegetables. Journal Food Science, v.41, p.379382. 1976.

SARANTOPOULOS, C.I.G.L; OLIVEIRA, L.M.;TELES, C.S.COPPELMANS, S.A. Efeito da embalagem e da temperatura de estocagem na qualidade de couve minimamente processada. Brazilian Jounal Food Technology, v.6, p.185-190, 2003.

SAKR, S.; NOUBAHNI, M.; BOURBOULOUX, A.; RIESMEIER, J.; FROMMER, W.B., SAUER, N., DELROT, S. Cutting, ageing and expression of plant membrane transporters. Biochymical and Biophysical Acta, v.1330, p.207-216, 1997.

THOMAS, H.; STODDART, J.L. Leaf senescence. Annual Review Plant Physiology, v.31, p.83-111, 1980.

VITTI, M.C.; KLUGE, R.A., YAMAMOTTO, L.K.; JACOMINO, A.P. Comportamento da beterraba minimamente processada em diferentes espessuras de corte. Horticultura Brasileira, Brasilia, v.21, p.623-629, 2003.

WATADA, A.E.; ABE, K.; YAMUCHI, N. Physiological activities of partially processed fruits and vegetables. Food Technology, v.44, p.116-122, 1990.

WATADA, A.E.; KO, N.P.; MINOTT, D.A. Factors affecting quality of fresh-cut horticultural products. Postharvest Biology Technology. v.9, n.2, p.115-126, 1996

WHITAKER, J.R.; LEE, C.Y. Recent advances in chemistry of enzymatic broning: na overview. In: LEE, C.Y.; WHITAKER, J.R. (Eds.). Enzymatic browing and its prevention. Washington, D.C., ACS, 1995. p.2-7.

WILEY, R.C. Minimally processed refrigerated fruis and vegetables. London: Chapman \& Hall, 1994. $357 \mathrm{p}$. 